TITLE:

\title{
Evaluation on plastic deformation property of copper nano-film by nano-scale cantilever specimen
}

\section{AUTHOR(S):}

Sumigawa, Takashi; Shishido, Tetsuya; Murakami, Tadashi; Iwasaki, Tomio; Kitamura, Takayuki

\section{CITATION:}

Sumigawa, Takashi ... [et al]. Evaluation on plastic deformation property of copper nanofilm by nano-scale cantilever specimen. Thin Solid Films 2010, 518(21): 6040-6047

\section{ISSUE DATE:}

2010-08-31

URL:

http://hdl.handle.net/2433/128864

\section{RIGHT:}

(c) 2010 Elsevier B.V.; この論文は出版社版でありません。引用の際には 出版社版をご確認ご利用ください。; This is not the published version. Please cite only the published version. 


\section{Evaluation on Plastic Deformation Property of Copper Nano-Film by Nano-Scale Cantilever Specimen}

Authors: Takashi Sumigawa ${ }^{1 *}$, Tetsuya Shishido ${ }^{1}$, Tadashi Murakami ${ }^{1}$, Tomio Iwasaki ${ }^{2}$, and Takayuki Kitamura ${ }^{1}$

Affiliations:

1 Department of Mechanical Engineering and Science, Kyoto University, Kyoto 606-8501, Japan

2 Mechanical Engineering Research Laboratory, Hitachi, Ltd., Katsuta, Ibaraki 312-0034, Japan

*Corresponding author

\section{Abstract}

We investigate the elasto-plastic deformation properties of a 20 -nm-thick copper $(\mathrm{Cu})$ thin film. A nanoscale cantilever specimen is fabricated from multilayer thin films, where the $\mathrm{Cu}$ thin film is sandwiched between a silicon nitride layer and a silicon substrate. During bending, the load, $P$, and displacement, $d$, are carefully monitored using an electron microscope, and a distinct non-linearity is observed. The plastic constitutive equation of the $\mathrm{Cu}$ thin film, which is assumed to obey a power hardening law $\left(\sigma=R \varepsilon^{n}\left(\sigma>\sigma_{\mathrm{y}}\right)\right)$, is inversely derived by finite element method fitting the experimental results. The residual stress in each layer is experimentally examined, and the effect is included in the inverse analysis. We obtain $\sigma=3316 \varepsilon^{0.29}[\mathrm{MPa}]$ and a yield stress of $765 \mathrm{MPa}$ for the $\mathrm{Cu}$ film. The yield stress is about 10 times higher than that of the bulk, and the exponent is also larger. Moreover, inverse analysis based on the bending experiment data, without considering the residual stress, gives a good approximation of the plastic law. This is because the plastic deformation preferentially takes place at the top and bottom surfaces, where the residual stress is relieved during fabrication of the specimen.

keywords: Film, Nano, Constitutive equation, Copper, Inverse analysis, Finite element method 


\section{Introduction}

Further miniaturization of advanced electronic devices requires a reduction in the thickness and width of the metal lines, resulting in sizes of several to several tens of nanometers [1-2]. It is necessary to accurately understand the material properties to design devices with sufficient strength to ensure device reliability. On the other hand, metals with dimensions less than a micrometer possess plastic deformation properties different from those of the bulk [3-5]. Furthermore, since the device components are surrounded by dissimilar materials [6-7], the resulting deformation constraints may affect the plastic behavior. Thus, nano-sized metal components in electronic devices are expected to show specific deformation properties due to both their size and their constraints.

Thin films deposited on substrates generally possess residual stress, due to the peculiar atomic arrangement and the difference in thermal expansion coefficients between the film and the substrate [8-9]. Consequently, the effects of residual stress should be taken into account in the analysis of the mechanical properties of thin films [10]. However, there has been no report on the plastic deformation properties of nano-sized metal components which includes the effects of residual stress.

The purpose of this study is to investigate the plastic deformation behavior of a nano-sized copper $(\mathrm{Cu})$ component with a thickness of $20 \mathrm{~nm}$ and an area of $280 \mathrm{~nm} \times$ $125 \mathrm{~nm}$, which is restrained by dissimilar materials. The effect of the residual stress on the elasto-plastic constitutive equation is also examined.

\section{Experimental Observation of the Plastic Deformation of a 20 -nm-thick $\mathrm{Cu}$ Film}

\subsection{Experimental Procedure}

We examine multi-layer thin films of $\mathrm{Cu}$ (20 nm thick) and silicon nitride ( $\mathrm{SiN}$ ) (500 nm thick), deposited on a silicon ( $\mathrm{Si}$ ) (100) substrate with a thickness of $500 \mu \mathrm{m}$ by magnetron sputtering at rates of 24 and $10.5 \mathrm{~nm} / \mathrm{min}$, respectively. Deposition is performed at a chamber pressure of $0.67 \mathrm{~Pa}$ after the native oxide layer on the substrate is removed by argon ion etching. Platinum $(\mathrm{Pt})$, carbon $(\mathrm{C})$, and tungsten $(\mathrm{W})$ layers are deposited to protect the $\mathrm{SiN}$ layer during the subsequent focused ion beam (FIB) processing.

Figure 1(a) illustrates the specimen configuration and loading [11-12]. The specimen is carved out of the multilayer material by focused ion beam processing. A load is applied to the $\mathrm{SiN}$ layer away from the $\mathrm{Cu}$ film. The displacement at the arm tip is monitored during the experiment using an electron microscope, as will be explained 
later. By varying the ratio of arm length to height, $l / h$, the deformation can be precisely measured, because the arm amplifies the displacement. In this study, $l / h$ is set to about 6 , considering the precision of FIB processing. Since the yield stresses of the Si substrate and the $\mathrm{SiN}$ layer are much higher (Si: $\left.\sigma_{\mathrm{y}}>3.4 \mathrm{GPa}[13], \mathrm{SiN}: \sigma_{\mathrm{y}}>8.4 \mathrm{GPa}[14]\right)$ than that of $\mathrm{Cu}$, the $\mathrm{Cu}$ thin film preferentially deforms after yielding.

The fabrication procedure is as follows.

(1) A block with a size of $10 \times 10 \times 10 \mu \mathrm{m}^{3}$ is carved out of the multilayer material. (Fig. 2(a))

(2) The block is picked up by a micro glass probe using electrostatic force. (Fig. 2(b))

(3) A gold $(\mathrm{Au})$ wire with a flat top is prepared, and the block is mounted using an adhesive. (Fig. 2(c))

(4) The block is formed into a cantilever-shaped specimen. (Fig. 2(d) from 1 to 3)

1. The side planes are processed by vertical FIB. (Fig. 2(d)-1)

2. The top and the bottom planes of the cantilever are processed by lateral FIB. (Fig. 2(d)-2)

3. The surfaces are finished to remove the layer damaged by the crude processing, and the shape of the interface edge is flattened (Fig. 2(d)-3)

The output voltage of the FIB processing is kept at $30 \mathrm{kV}$, and the currents in the crude processing and in the surface finishing are 5-10 nA and $10 \mathrm{pA}$, respectively.

Figure 3 shows the shape and dimension of the fabricated specimen. The $\mathrm{Cu}$ has dimensions of $280 \mathrm{~nm} \times 125 \mathrm{~nm} \times 20 \mathrm{~nm}$, and is sandwiched by Si and SiN.

The load is supplied by a small device consisting of a stage which can move in three orthogonal directions and a diamond chip with a load sensor, as shown in Fig. 4. The measurement range of the load is $0-100 \mu \mathrm{N}$. The gold wire with the specimen is set on the stage, and the cantilever is loaded by pushing it against the chip. The moving speed of the stage is $8 \mathrm{~nm} / \mathrm{s}$. The displacement at the specimen tip is measured using a transmission electron microscope (TEM) with the loading device installed. TEM observation is adopted because it has the advantages of precise measurement of displacement and precise location of the interfaces and contact area of the loading chip. Metallographic observation of the specimen interior is outside the scope of this work. Observations are carried out with an accelerating voltage of $200 \mathrm{kV}$ under vacuum $(1.5$ $\left.\times 10^{-5} \mathrm{~Pa}\right)$. 


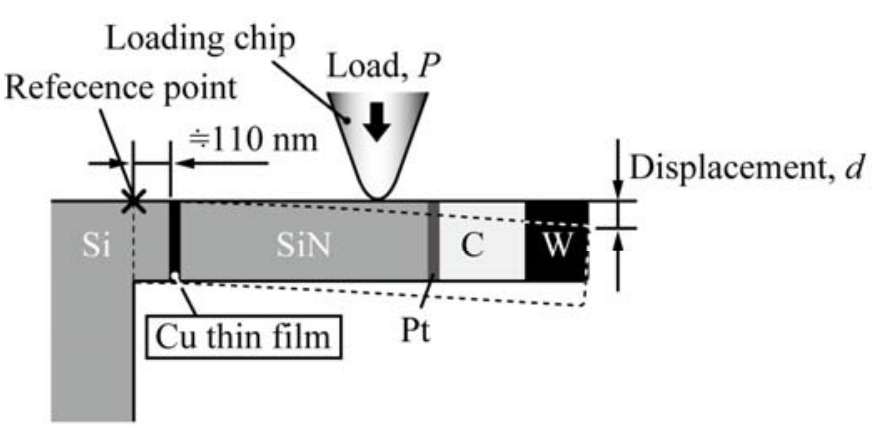

(a) Schematic view

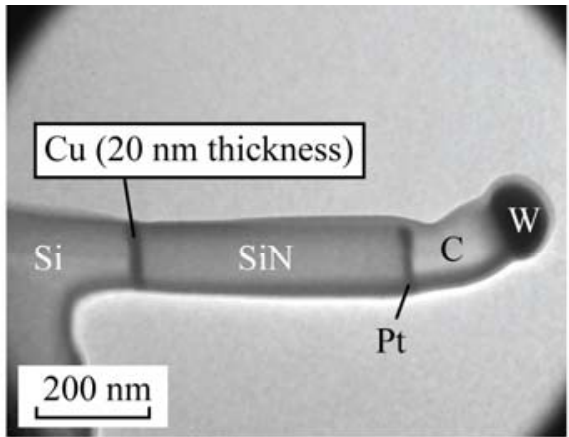

(b) TEM observation of specimen

Figure 1 Specimen configuration and loading.

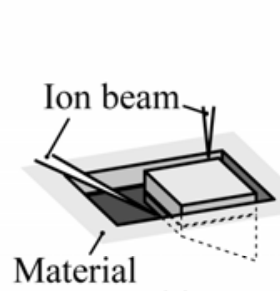

(a)

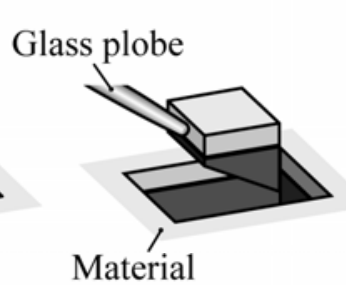

(b)

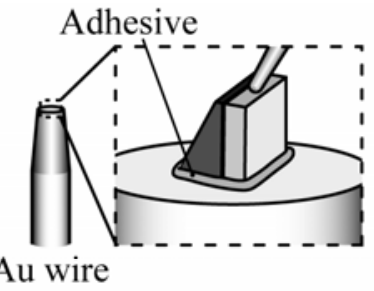

(c)

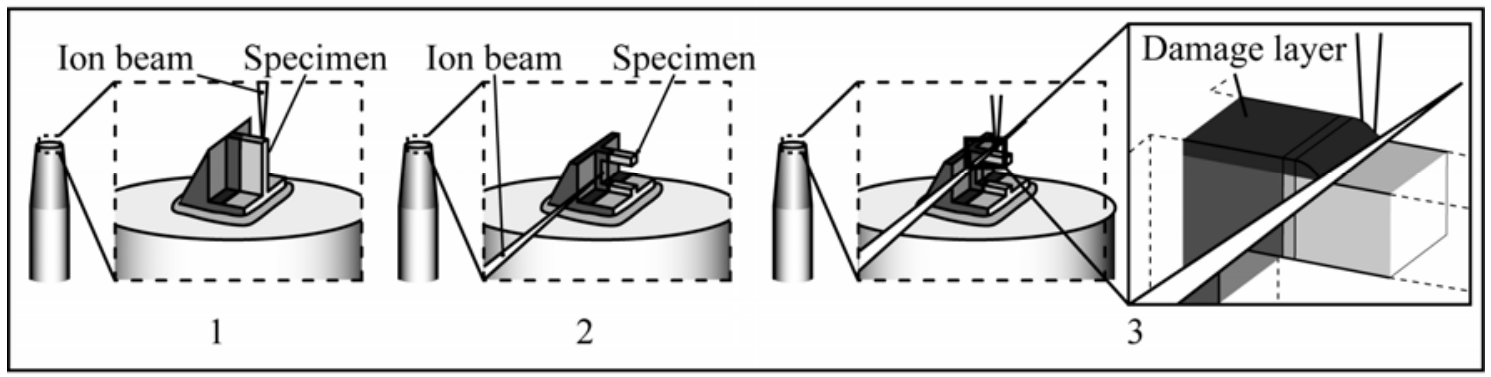

(d)

Figure 2 Specimen fabrication procedure.

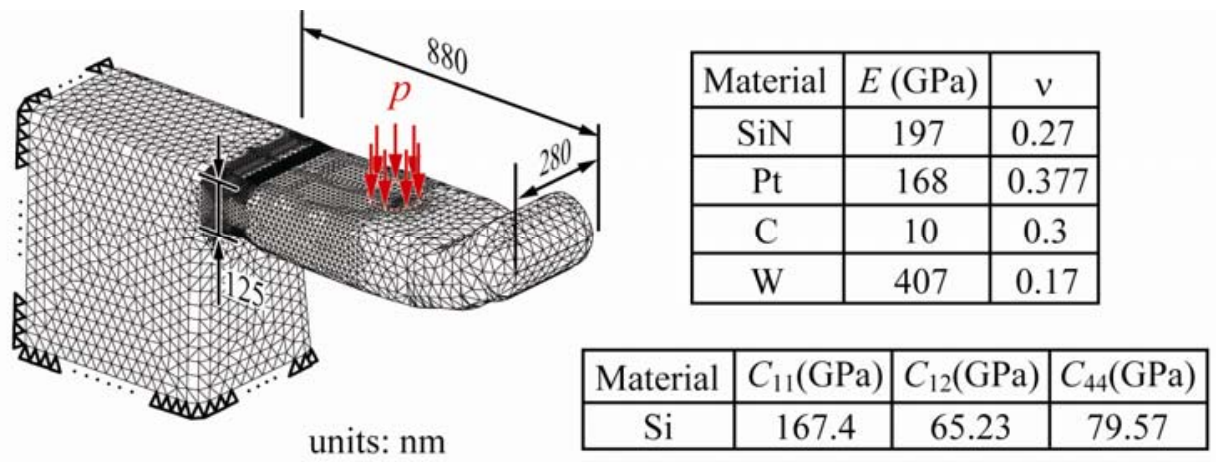

Figure 3 Specimen and its mesh division for FEM analysis. 


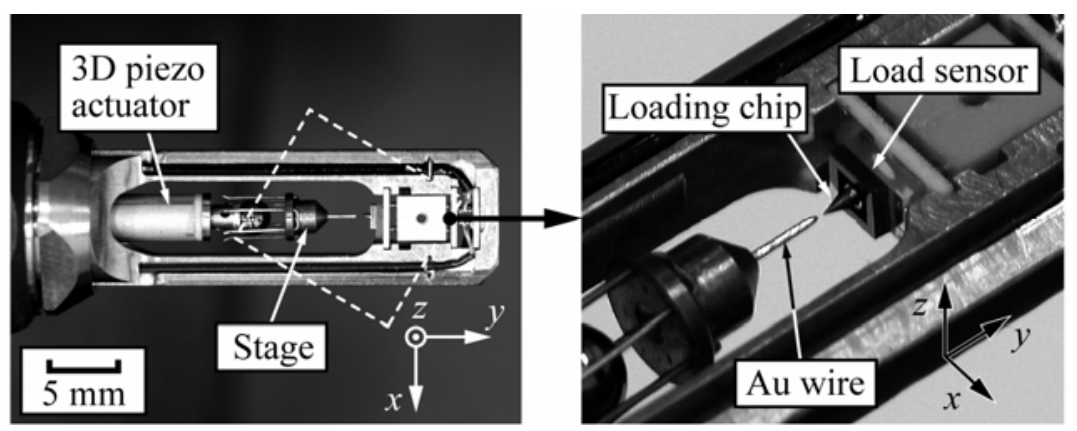

Figure 4 The loading device used in the deformation experiment.

\subsection{Experimental Results}

Figure 5 shows TEM images before and during loading, the relationship between the applied load, $P$, and the time, $t,(P$ - $t$ relationship), and the relationship between the $P$ and the displacement at the cantilever tip (arm end of specimen), $d,(P-d$ relationship). Here, the $d$ represents the relative displacement from the reference point placed at the root of the cantilever (See Fig. 1). The loading point and the $\mathrm{Cu}$ thin film are clearly observed by TEM, and the displacement at the arm end can be quantitatively measured from the images. The $P$ - $t$ relationship indicates that the fluctuation of the load is very small. Especially, the accuracy of the load in the high load range $(P>4.0 \mu \mathrm{N})$ is about $\pm 0.1 \mu \mathrm{N}$. The displacement increases linearly with increasing load at low loading levels, but shows clear nonlinear behavior beyond $P=3 \mu \mathrm{N}$, with the degree of nonlinearity greatly exceeding the measurement accuracy (about $5 \mathrm{~nm}$ ). We carry out an additional experiment by using another specimen with similar size, where it is unloaded after the loading up to the non-linear $P-d$ region. The $P-d$ relation in the unloading clearly shows the hysteresis (residual strain), and this indicates that the specimen is plastically deformed. The TEM image after the breaking points out that the shapes of the Si and the SiN parts correspond to the initial ones. This result indicates that they elastically deforms during the loading.

The solid line shows the relation obtained by elastic finite element method (FEM) simulation, where all materials are assumed to be linear-elastic and the Young's modulus of the bulk material $\left(E_{\mathrm{Cu}}=129 \mathrm{GPa}\right)$ is used for the $\mathrm{Cu}$ thin film. The detailed FEM procedure is described in the next section. The good agreement with the experimental results below $P=3 \mu \mathrm{N}$ indicates that the structure of the thin film has little effect on the Young's modulus. 


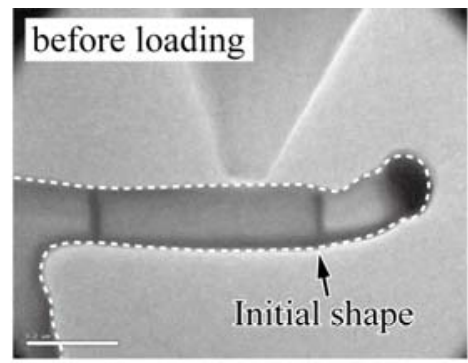

$\overline{200 \mathrm{~nm}}$
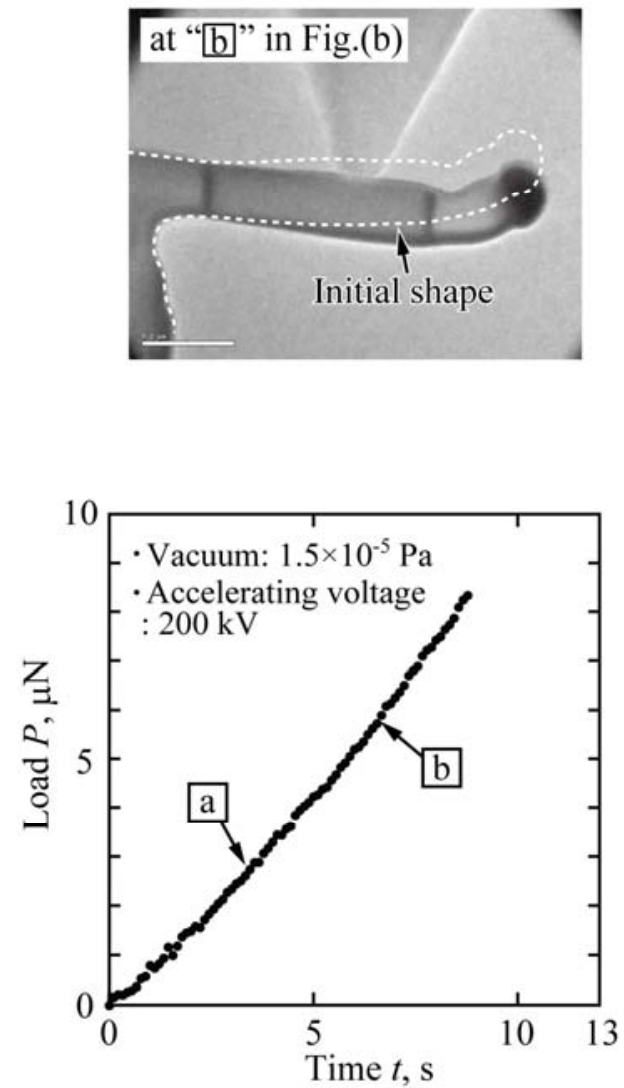

(b)
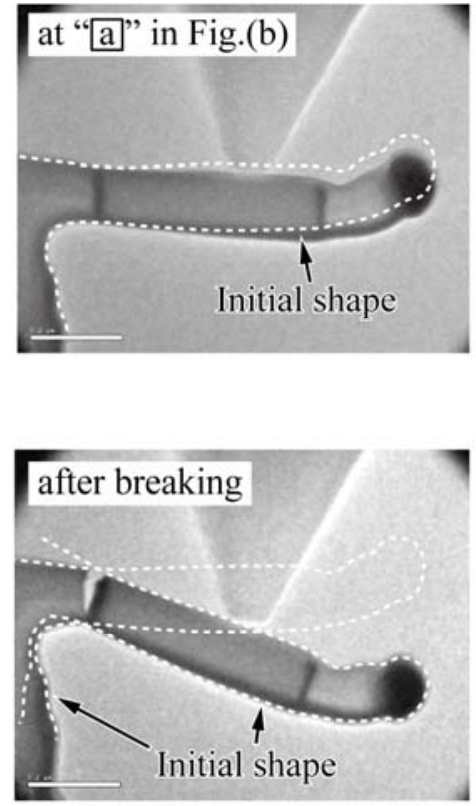

(a)

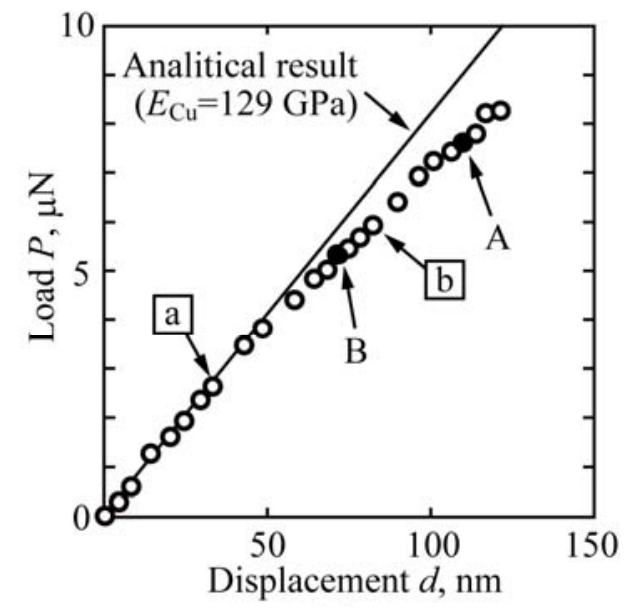

(c)

Figure 5 Deformation behavior of the specimen: (a) TEM images, (b) Load-time curve, and (c) Load-displacement curve. The displacement magnified by the arm includes not only the deformation of $\mathrm{Cu}$ but also elastic ones of Si substrate and $\mathrm{SiN}$ layer. The deformation of $\mathrm{Cu}$ thin film is small because the thickness is very thin.

\section{Elasto-Plastic Behavior}

\subsection{Procedure for Inverse Analysis}

Since the $\mathrm{Cu}$ portion is very thin, the deformation cannot be directly obtained by the TEM image. The elasto-plastic constitutive equation of the $\mathrm{Cu}$ thin film is derived 
by inverse analysis using a three-dimensional FEM.

Using the Von Mises equivalent stress and strain, the deformation behavior of the $\mathrm{Cu}$ thin film is described by

$$
\sigma=\left\{\begin{array}{lll}
E \varepsilon & , \text { for } & \sigma \leq \sigma_{y} \\
R \varepsilon^{n} & , \text { for } & \sigma \geq \sigma_{y}
\end{array},\right.
$$

where $E, R, n, \varepsilon$, and $\sigma_{y}$ are the Young's modulus, strength coefficient, strain hardening exponent, total effective strain, and yield stress, respectively. At the yield point, we have

$$
\frac{\sigma_{\mathrm{y}}}{R}=\left(\frac{\sigma_{\mathrm{y}}}{E}\right)^{n}
$$

so $R$ is given by the unknown quantities $E, \sigma_{\mathrm{y}}$, and $n$. Since we can use the bulk elastic constants, as shown in Sec. 2.2, the only unknown parameters are $\sigma_{\mathrm{y}}$ and $n$.

The derivation procedure of $\sigma_{\mathrm{y}}$ and $n$ is as follows:

(1) Arbitrary points (points A and B) are selected in the non-linear portion of the load-displacement curve (Fig. 6(a)).

(2) The combination of $\sigma_{\mathrm{y}}$ and $n$, which fulfills the displacement at point $\mathrm{A}$ as measured by the experiment, is found using elasto-plastic FEM by trial-and-error (Fig. 6(b)). Since two parameters can not be determined at once from one experimental point, this establishes a relationship between $\sigma_{\mathrm{y}}$ and $n$, as schematically shown in Fig. 6(b).

(3) In the same way, the combination of $\sigma_{\mathrm{y}}$ and $n$ at point $\mathrm{B}$ is derived through FEM (Fig. 6(c)). The broken line in Fig. 6(c) shows the relationship determined from point $\mathrm{B}$.

(4) The intersection between the two lines gives the combination of $\sigma_{\mathrm{y}}$ and $n$ (Fig. $6(c))$.

We pick the points $\mathrm{A}(106.0 \mathrm{~nm}, 7.4 \mu \mathrm{N})$ and $\mathrm{B}(71.0 \mathrm{~nm}, 5.3 \mu \mathrm{N})$ in the $P-d$ relationship for the inverse analysis.

For the accurate analysis, it is important to identify the exact shape of the specimen. The FEM model is created using the following procedure and commercial three-dimensional CAD software:

(1) The specimen is divided into several regions on the basis of TEM and scanning 
electron microscope images. Regions with complicated shapes are divided into still smaller regions (Fig. 7(a)).

(2) The outlines of the cross-sections of the cantilever are identified (Fig. 7(b)).

(3) Combining the outlines by spline interpolation, the analytical model is constructed (Fig. 7(c)).

The model is divided into meshes by the ABAQUS/CAE as shown in Fig. 3, where the region near the interface has a finer mesh. A perfect constraint condition is imposed on the left and bottom edges of the model.

The elastic constants in the analysis are summarized in Fig. 3. Here, the Young's modulus of the SiN layer, $E=197 \mathrm{GPa}$, is measured by a nano-indentation test. A uniform distributed load, $p$, is applied to the region where the loading chip makes contact.

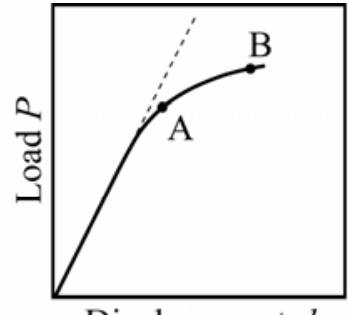

Displacement $d$

(a)

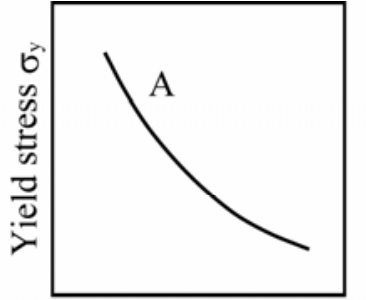

Hardening exponent $n$

(b)

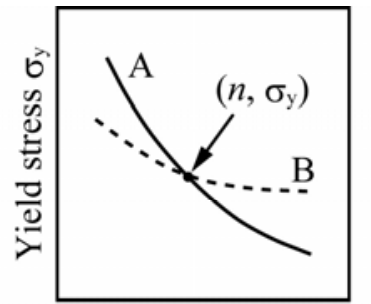

Hardening exponent $n$

(c)

Figure 6 Procedure for inverse analysis.

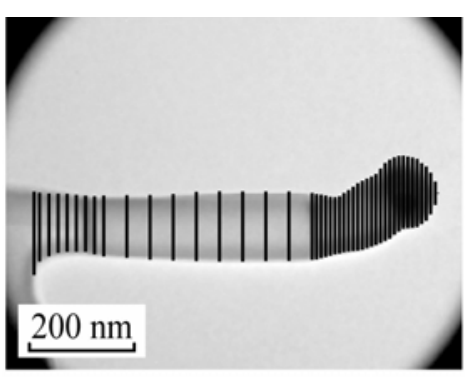

(a)

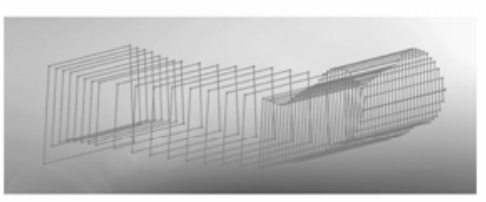

(b)

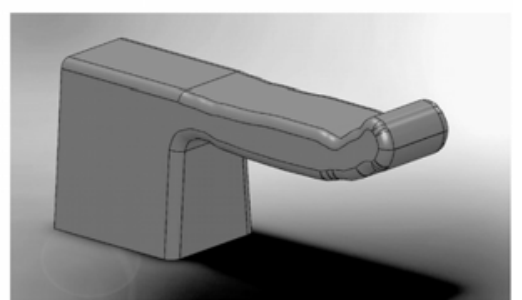

(c)

Figure 7 Procedure for construction of the analytical model.

\subsection{Constitutive Equation of Plasticity}

Figure 8 shows the $\sigma_{\mathrm{y}}-n$ relationships at points $\mathrm{A}$ and $\mathrm{B}$ obtained by the inverse analysis. While both relationships are approximately linear, the gradients are different. The point of intersection gives the following elasto-plastic constitutive equation for the 20-nm-thick $\mathrm{Cu}$ thin film: 


$$
\sigma=\left\{\begin{array}{lll}
129000 \varepsilon & \text {, for } \quad \sigma \leq 728[\mathrm{MPa}] \\
3423 \varepsilon^{0.3} & \text {, for } \sigma \geq 728 \quad[\mathrm{MPa}]
\end{array}\right.
$$

Figure 9(a) shows the $P-d$ relationship (blue broken line) obtained by the FEM on the basis of Eq. (3). This demonstrates that Eq. (3) consistently reproduces the nonlinearity of the $\mathrm{Cu}$ thin film.

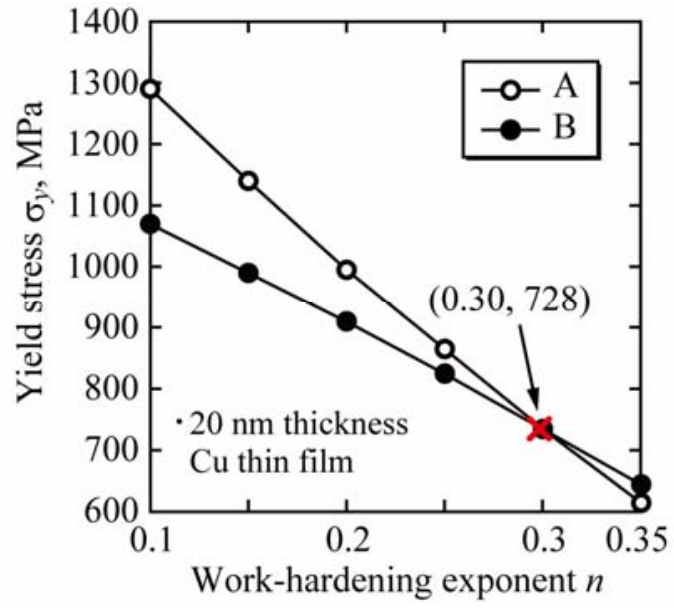

Figure $8 \sigma_{\mathrm{y}}-n$ relationships of points $\mathrm{A}$ and $\mathrm{B}$

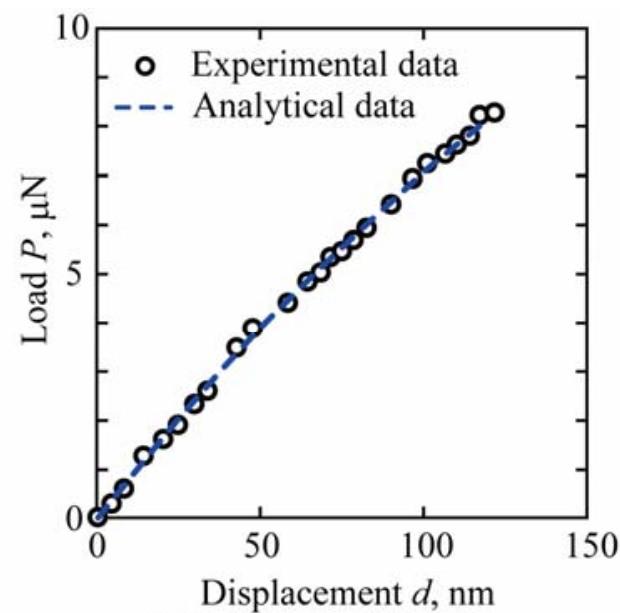

(a) without residual stress

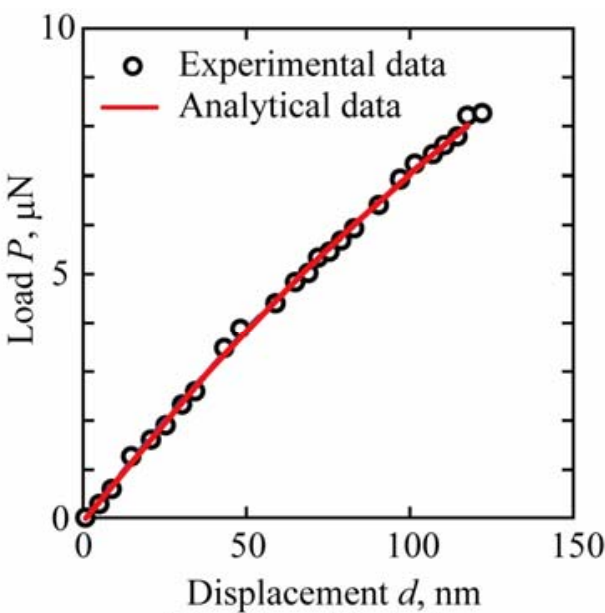

(b) with residual stress

Figure 9 Loading curves obtained from the inverse analysis.

\section{Influence of Residual Stress on the Plastic Behavior}

\subsection{Evaluation of Residual Stress}

The residual stress in the thin film is estimated by the deflection of the material [10]. Not only the multi-layered material ( $\mathrm{Si}($ substrate) $/ \mathrm{Cu} / \mathrm{SiN}$ ) but also single-layered material $(\mathrm{Si}($ substrate $) / \mathrm{Cu})$ is prepared, in order to independently evaluate the residual 
stress of each layer. Hereafter, these are designated as "multilayer material", and "Cu-layer material", respectively. The latter gives us $\delta_{\mathrm{Cu}}$, and $\delta_{\mathrm{SiN}}$ is extracted by deducting $\delta_{\mathrm{Cu}}$ from the previously-obtained $\delta_{\mathrm{Cu}+\mathrm{SiN}}$. Strip specimens with a size of $5 \mathrm{~mm}$ $\times 48 \mathrm{~mm}$ are cut from the material and the deflections are measured using a CCD laser displacement meter (KEYENCE: LK-G10, repeat accuracy: $0.01 \mu \mathrm{m}$ ).

The average deflections of the specimens are evaluated to be $\delta_{\mathrm{Cu}+\mathrm{SiN}}=-20.89 \mu \mathrm{m}$ and $\delta_{\mathrm{Cu}}=2.43 \mu \mathrm{m}$, respectively. The residual stress of the thin film is inversely obtained by FEM. The results are $\sigma_{\mathrm{Cu}}=760 \mathrm{MPa}$ (tensile stress) and $\sigma_{\mathrm{SiN}}=-290 \mathrm{MPa}$ (compressive stress), respectively.

\subsection{Plastic Behavior}

Before the inverse analysis of plastic deformation, we examined the distribution of residual stress in the specimen. The residual stresses (Cu: $760 \mathrm{MPa}, \mathrm{SiN}$ : -290 MPa) are imposed on the $\mathrm{Cu}$ and $\mathrm{SiN}$ layers in the specimen model shown in Fig. 3. Then, they are allowed to relax by FEM. Figure 10 shows the distribution of normal stress, $\sigma_{z}$, in the $\mathrm{Cu}$ thin film before the inverse analysis. Although the average value of internal stress is about $760 \mathrm{MPa}$, it is almost zero near the outer surfaces (Fig. 10(a)).

The FEM inverse-analysis considering the residual stresses in the $\mathrm{Cu}$ thin film and the SiN layer is carried out for points $\mathrm{A}(106.0 \mathrm{~nm}, 7.4 \mu \mathrm{N})$ and $\mathrm{B}(71.0 \mathrm{~nm}, 5.3 \mu \mathrm{N})$ in the $P$ - $d$ curve. Figure 11 shows the $\sigma_{\mathrm{y}}-n$ relationships, and the elasto-plastic constitutive equation of the $\mathrm{Cu}$ thin film is given by the intersection as follows:

$$
\sigma=\left\{\begin{array}{l}
129000 \varepsilon \quad \text {, for } \sigma \leq 765[\mathrm{MPa}] \\
3316 \varepsilon^{0.3}, \text { for } \sigma \geq 765 \quad[\mathrm{MPa}]
\end{array}\right.
$$

Figure 9(b) shows the load-displacement relationship (red solid line) obtained analytically by FEM on the basis of Eq. (4). The nonlinearity of the $\mathrm{Cu}$ thin film is well-reproduced.

Figure 12 shows a comparison of stress-strain relationships between the $\mathrm{Cu}$ thin films with and without residual stress, which reveals that the effect of the residual stress is not significant in the bending experiment. The difference in yield stresses is about 40 $\mathrm{MPa}$, despite a residual stress of $760 \mathrm{MPa}$. The residual stress, which is in the plane of the film, decreases near the outer surface of the specimen (See Fig. 10(a)) because the stress must be zero at a free surface. In bending, the stress concentrates near the upper and lower outer surfaces of the specimen, and yielding preferentially occurred there. Consequently, the effect of the residual stress on the initial yield is small in this testing 
method. In other words, the method adopted here (Fig. 1) gives a very similar relationship (Eq. (3)) to the universal one (Eq. (5)), despite the lack of residual stress. Thus, as a first approximation we can ignore the residual stress when we seek the constitutive relation by this experimental method.

Figure 12 shows the tensile behavior of a 200-nm-thick $\mathrm{Cu}$ thin film [11] and a $\mathrm{Cu}$ bulk material (average diameter of grains is $58 \mu \mathrm{m}$ ) [15] for comparison. The yield stress of the bulk material is the lowest $\left(\sigma_{\mathrm{y}}=60 \mathrm{MPa}\right)$, and increases with decreasing thickness of the thin film $\left(200 \mathrm{~nm}\right.$ thick: $\sigma_{\mathrm{y}}=345 \mathrm{MPa}, 20 \mathrm{~nm}$-thick: $\sigma_{\mathrm{y}}=765 \mathrm{MPa}$ (with residual stress)).

If the mean grain diameter is assumed to be $20 \mathrm{~nm}$, the Hall-Petch relation of spattered $\mathrm{Cu}$ thin films [16] gives the yield stress of about $1 \mathrm{GPa}$. Similarly, it gives about $250 \mathrm{MPa}$ for the grain diameter of $200 \mathrm{~nm}$. Although the yield stress obtained for the 20-nm-thickness film and the $200 \mathrm{~nm}$-one has a slight deviation, they follow the Hall-Petch relation considering the difference in the processing condition. In short, the result indicates that the high yield stress is due to the stacking of dislocations at the interfaces, $\mathrm{Si} / \mathrm{Cu}$ and $\mathrm{SiN} / \mathrm{Cu}$.

Figures 13(a) and (b) show the development of plastic strain inside the $\mathrm{Cu}$ thin film of the specimen. During bending, plastic deformation should take place simultaneously in the upper and lower regions. For the $\mathrm{Cu}$ thin film without residual stress, this is in fact what occurs (See Fig. 13(b)). However, when residual stress is included, the plastic strain appeared primarily at the bottom region. This is due to the in-plane tensile residual stress of the $\mathrm{Cu}$ thin film. The hydrostatic stress, which does not contribute to the plastic (slip) deformation, increases in the upper region, while the shear stress component, which strongly involves slip deformation, develops in the lower region.

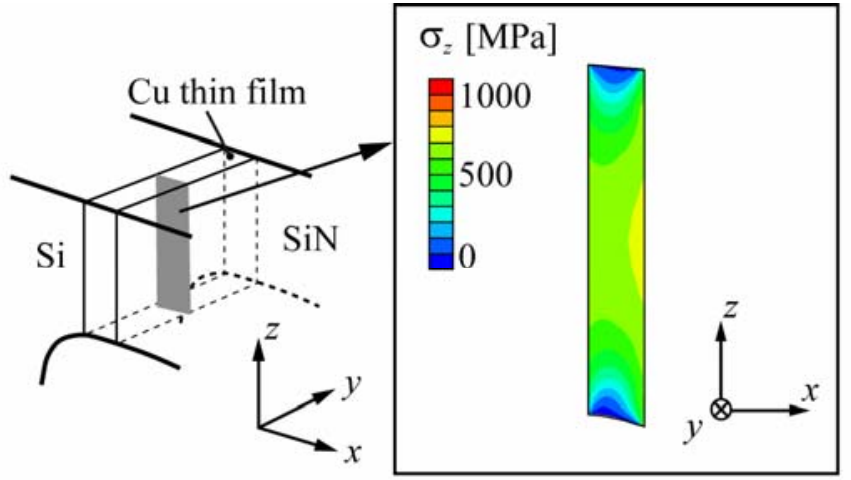

(a)

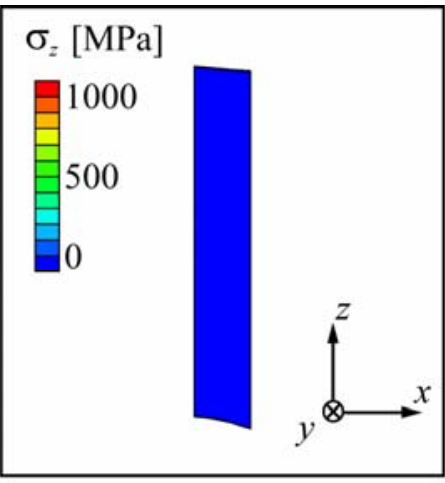

(b)

Figure 10 Distribution of normal stress, $\sigma_{z z}$, before the inverse analysis: (a) with residual stress, (b) without residual stress. 


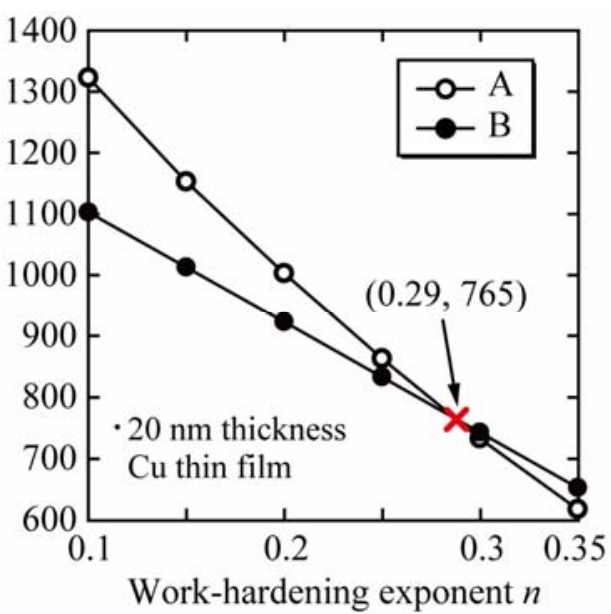

Figure $11 \sigma_{\mathrm{y}}-n$ relationships of points A and B.

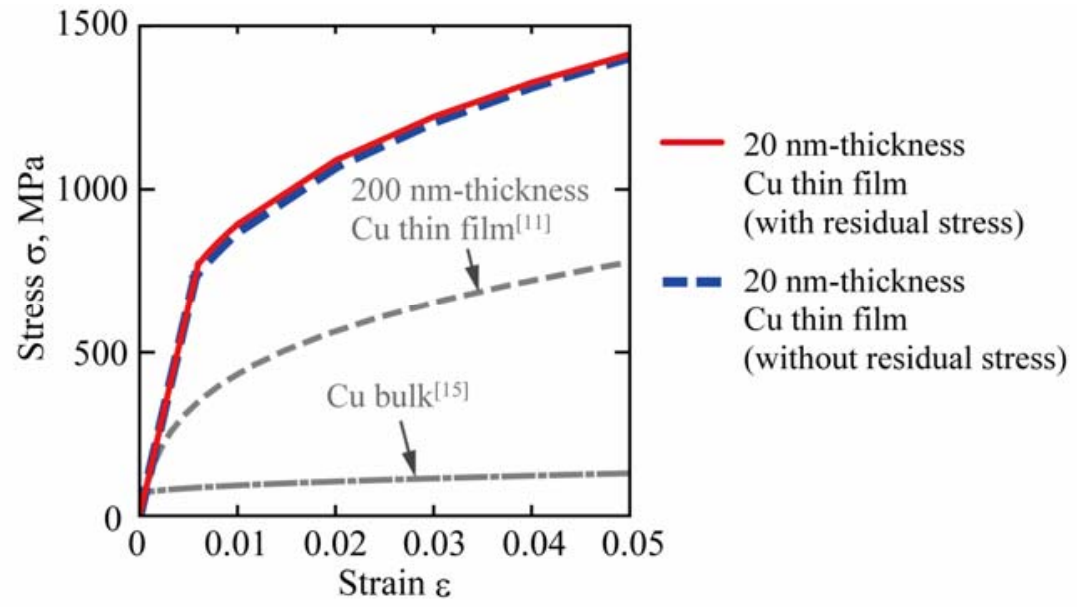

Figure 12 Stress-strain relationships. The blue broken line shows Eq. (3) without residual stress, while the red solid line represents Eq. (4) with residual stress. 


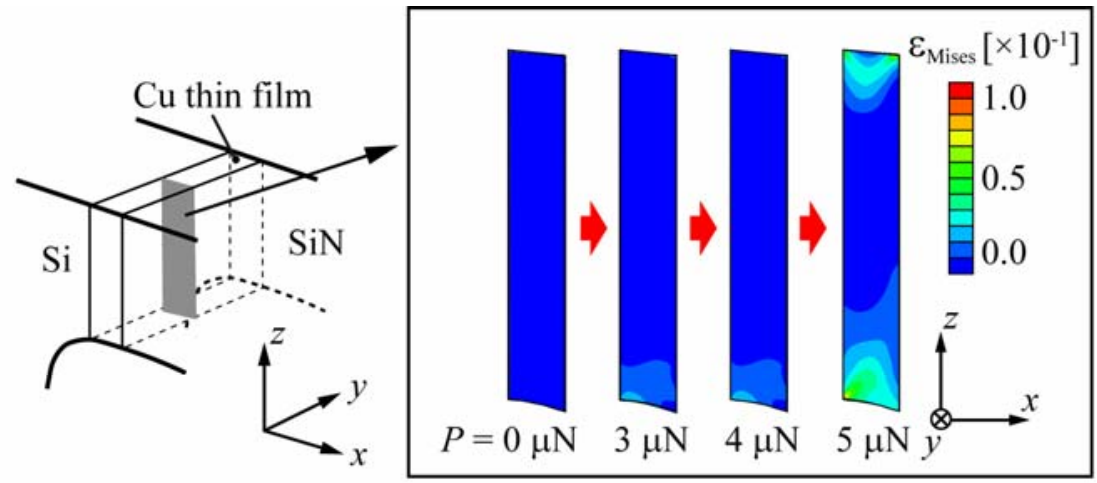

(a)

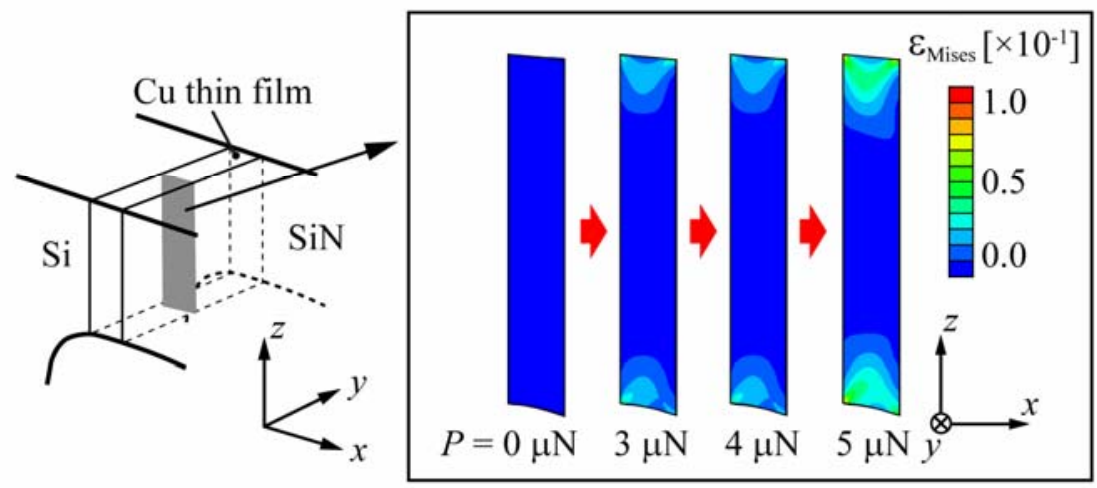

(b)

Figure 13 Development of equivalent plastic strain: (a) with residual stress, (b) without residual stress.

\section{Conclusions}

A nano-scale specimen is carved out of a multi-layered material in which a 20-nm-thick $\mathrm{Cu}$ thin film is sandwiched between a SiN layer and a Si substrate. We then experimentally and computationally investigate the plastic deformation behavior and the effects of residual stress on the specimen. We developed a methodology to test the mechanical behavior of nano-components. By adopting a specimen with a long arm, the displacement of the arm tip is precisely measured in a bending experiment involving a nano-cantilever. A distinct nonlinearity is identified in the load-displacement relationship. The residual stresses of the $\mathrm{Cu}$ thin film and the $\mathrm{SiN}$ layer were $\sigma_{\mathrm{Cu}}=760$ $\mathrm{MPa}$ (tensile stress) and $\sigma_{\mathrm{SiN}}=-300 \mathrm{MPa}$ (compressive stress), respectively. The elasto-plastic constitutive equation of the 20 -nm-thick $\mathrm{Cu}$ thin film is evaluated as follows:

$$
\sigma=\left\{\begin{array}{lll}
129000 \varepsilon & \text {,for } \sigma \leq 765[\mathrm{MPa}] \\
3316 \varepsilon^{0.3} & \text {,for } \quad \sigma \geq 765 \quad[\mathrm{MPa}]
\end{array},\right.
$$

taking into account the influence of residual stress. The yield stress of the $\mathrm{Cu}$ thin film 
is about 10 times higher than that of the bulk, and the exponent is larger as well. In this method, the effect of residual stress on the stress-strain relationship is limited, because fabrication of the cantilever relaxed the residual stress near the outer surfaces of the specimen where the initial yielding occurs under the experimental loading. This indicates that we can derive the precise constitutive equation by this method without requiring information on the residual stress.

\section{Acknowledgment}

This research was supported in part by a Grant-in-Aid for Scientific Research (S)(No.21226005) from the Japan Society of the Promotion of Science, and by a Grant-in-Aid for Young Scientists (A)(No. 21686013) from the Ministry of Education, Culture, Sports, Science and Technology, Japan. 


\section{References:}

[1] B. Michel, A. Bernard, A. Bietsch, E. Delamarche, M. Geissler, D. Juncker, H. Kind, J.P. Renault, H. Rothuizen, H. Schmid, P. Schmidt-Winkel, R. Stutz, H. Wolf, IBM J. Res. Dev. 45 (2001) 697.

[2] H.K. Seung, P. Inkyu, P. Heng, P.G. Costas, P.P. Albert, K.L. Christine, M.J.F. Jean, Nano Lett. 7 (2007) 1869.

[3] M.D. Uchic, D.M. Dimiduk, J.N. Florando, W.D. Nix, Science, 305 (2004) 986.

[4] J.R. Greer, W.C. Oliver, W.D. Nix, Acta Mater. 53 (2005) 1821.

[5] C.R. Barrett, W.D. Nix, A.S. Tetelman, The Principles of Engineering Materials, Prentice-Hall, New Jersey, 1973, p. 251.

[6] S. Krongelb, L.T. Romankiw, J.A. Tornello, IBM J. Res. Dev. 42 (1998) 575.

[7] Y. Kawamura, T. Sumigawa, T. Kitamura, T. Kugimiya and T. Kawakami, J. Comput. Sci. Technol. 3 (2009) 159.

[8] J. Bottiger, J. Chevallier, K. Kringhoj, K.O. Schweitz, Adhesion aspects of thin films, VSP, Netherlands, vol. 1, 2001, p. 1.

[9] R. Koch, J. Phys.: Condens. Matter. 6 (1994) 9519.

[10] T. Kitamura, H. Hirakata, T. Itsuji, Eng. Fract. Mech. 70 (2003) 2089.

[11] H. Hirakata, Y. Takahashi, D. Van Truong, T. Kitamura, Int. J. Fract. 145 (2007) 261.

[12] Y. Takahashi, H. Hirakata, T. Kitamura, Thin Solid Films 516 (2008) 1925.

[13] W.D. Nix, Metall. Mater. Trans. 20 (1989) 2217.

[14] K.S. Lee, S. Wuttiphan, X.Z Hu, S.K. Lee, B.R. Lawn, J. Am. Ceram. Soc. 81 (1998) 571.

[15] ASM Handbook, Mechanical Testing and Evaluation, vol. 8, 2000, p.103.

[16] J.A. Ruud, D. Josell, and F. Spaepen, J. Mater. Res. 8 (1993) 112. 